\title{
Finding Fault in Organisations - Reconceptualising the Role of Senior Managers in \\ Corporate Manslaughter
}

\section{Luke Price, University of Exeter School of Law}

\begin{abstract}
The Corporate Manslaughter and Corporate Homicide Act 2007 purports to move away from the identification doctrine, towards a genuinely organisational model of corporate liability. There is a risk, however, that insistence upon the involvement of senior management in corporate manslaughter will reduce the Act to doing no more than aggregating individual misconduct. Such an approach would fail both to encompass the culpability of the organisation as more than just a collection of individuals, and to offer an effective tool for the prosecution of large organisations. I argue that the senior management requirement should not be interpreted as focusing on individuals, but on the authoritative systems of work that organisations impose upon their employees. Inherent in large organisations is a corporate structure, determining the meaning and value of what employees perceive and the boundaries and direction of their work. These structures emerge from the involvement of senior managers, whose rank and role within organisations enables them to contribute to the development of corporate structure. Through insistence on the involvement of these corporate architects and surveyors, the 2007 Act may be seen to emphasise the role of the organisation in corporate manslaughter, identifying truly corporate culpability.
\end{abstract}




\section{Introduction}

Who, or what, commits the crime of corporate manslaughter? Established legal doctrine dictates that the offence exists, yet at its core there is a fundamental dilemma. Does corporate liability arise because individual fault is transferred to the organisation, or is the organisation itself at fault?

With the arrival of the Corporate Manslaughter and Corporate Homicide Act 2007 comes a new framework for holding organisations accountable. By expanding the application of corporate manslaughter beyond business corporations, the 2007 Act has brought issues of organisational fault into heightened focus. Corporate manslaughter carries newfound relevance to the operations of a diverse range of organisations, both private and public. Corporations, government departments, police forces, partnerships, trade unions and employers' unions all fall within the scope of the 2007 Act. ${ }^{1}$ Corporate manslaughter is no longer a concept affecting simply business organisations. Questions of corporate liability have reached a newfound level of relevance and importance.

However, the Act has failed to resolve the underlying question of whether individual or organisational fault is the basis of corporate liability. Instead, by demanding that senior management be a substantial element of corporate culpability, the new law has created room for confusion. There remains the possibility that corporate manslaughter has retained its focus on individual fault by simply allowing for its aggregation, leaving the

\footnotetext{
${ }^{1}$ Corporate Manslaughter and Corporate Homicide Act 2007, s 1(2).
} 
new statutory offence caught between a metaphorical and genuine acceptance of the organisation as independently blameworthy. ${ }^{2}$

The common law of corporate manslaughter, with its insistence upon identifying one faulty individual, placed crippling restrictions on the offence. The new law aims to expand the reach of corporate liability for manslaughter, but with the ambiguity of the senior management requirement risks becoming wholly unhelpful in the prosecution of organisations. There is a need for clarity: do individuals commit corporate manslaughter by acting for the organisation, or can organisations commit manslaughter in their own right?

If senior management is treated as nothing more than a collection of individuals, the 2007 Act represents little more than a shift from considering individual fault towards considering aggregated individual fault. If this is the case, then serious questions arise over whether the Act aggregates enough conduct by the right individuals. Such is the variability of job titles between organisations that it will often be unclear who the senior managers of an organisation are, and corporate members beyond senior management can play significant roles in corporate misconduct.

Even if aggregated individual fault is considered in the absence of a senior management requirement, it will always be too narrow to capture the extent of fault involved in corporate liability. When actors are part of a group, individual innocence can collectively contribute to culpable consequences, particularly within the context of an organisation. Corporate environments can affect both the type, and impact, of individual

\footnotetext{
${ }^{2}$ Celia Wells, 'Corporate Criminal Liability in England and Wales' in Mark Pieth and Radha Ivory (eds), Corporate Criminal Liability: Emergence, Convergence, and Risk (Springer 2011), 109.
} 
action within their bounds. Actors within an organisation may behave without fault, but the output of the organisation will still warrant blame and punishment.

Individual fault, however aggregated, will never fully explain corporate culpability. Organisations will always add an additional dimension, and there is a corresponding need to characterise what organisations add to the picture. My suggestion is that the missing consideration has been the role of the organisation as an authoritative employer. Employer status has so far been used to attribute individual fault vicariously to organisations, but its importance reaches considerably further. Organisations, as employers, are authoritative, holding power and influence over their employees. ${ }^{3}$ They impose systems of work upon those employees, and inherent in these systems are structures that impose pressures and constraints upon members of the organisation. ${ }^{4}$ Corporate structure determines the direction and boundaries of behaviour within its confines. ${ }^{5}$ Through directing action, organisations attract attributions of fault and blame that, while arising out of individual action, are not dependent upon individual fault. Understood as imposing authoritative systems of employment, organisations become culpable in their own right.

Importantly, though, not every pressure within an organisation originates in a corporate system of work. Structure presses down upon employees, but some dynamics emerge upwards: whether from dominant individuals, from subgroups or out of the mere existence of a group of individuals working within one environment. ${ }^{6}$ These bottom-up dynamics arise in the corporate context, but do not have their origins in the organisation

\footnotetext{
${ }^{3}$ R. H. Coase, 'The Nature of the Firm' (1937) 4 Economica 386, 404.

${ }^{4}$ Michael Lounsbury and Marc Ventresca, 'The New Structuralism in Organizational Theory' (2003) 10 Organization 457, 459.

5 Philip Anderson, 'Complexity Theory and Organization Science' (1999) 10 Organization Science 216, 228.

${ }^{6}$ Julian Pratt, Pat Gordon and Diane Plamping, Working Whole Systems: Putting Theory into Practice in Organisations (2nd edn, Radcliffe 2005), 13.
} 
itself. Only the top-down constraints imposed by an organisation's structure are truly corporate, and this places an important limit on corporate liability. In order to distinguish corporate structure from other dynamics that are incidental to organisational settings, we need to look to the location of the relevant processes. That which is truly corporate is that which has been embedded in the organisation. Embedment relies upon policies being introduced, encouraged or permitted by founders or senior members.

While not limited by their initial design, corporate structures must always be built into the corporate entity. Behind corporate structures are corporate architects and surveyors who support this building process. The self-directing structures of an organisation find their origins in a process of adoption or acceptance by senior corporate members. ${ }^{7}$ It is at the point of identifying individual contributions that presuppose structure that the senior management requirement finds its importance. Only senior managers can contribute to corporate structure; corporate architects and surveyors necessarily operate at the upper echelons of organisations. Senior managers will always have a role in the formation of corporate structure, whether through explicit introduction, or active or passive acceptance. By insisting on the involvement of corporate architects and surveyors, the senior management requirement ensures only that which is truly corporate is attributed to the organisation.

With the recognition of organisations' authoritative systems and structures, it becomes possible to understand the 2007 Act as a coherent and effective means of holding organisations to account. The senior management requirement, previously considered overly restrictive and difficult to understand, takes on the function of a principled limit on

\footnotetext{
${ }^{7}$ Marcus W Dickson and others, 'An organizational climate regarding ethics: the outcome of leader values and the practices that reflect them' (2001) 12 The Leadership Quarterly 197, 208.
} 
corporate liability, preventing its overextension into the domains of culture, subgroups, or dominant individuals. The basis for corporate manslaughter can be clearly understood: it reflects an organisational, rather than individual, fault.

In what follows, I will in the second section provide a brief overview of the previous law of corporate manslaughter. Section 3 will offer an interpretation of the 2007 law as both a potential new beginning of organisational fault, and an arguably limited move towards liability based upon aggregated individual fault. This section will also consider the problems associated with an aggregative approach to corporate liability, and in an effort to avoid these difficulties I will in section 4 present an alternative approach. Organisations contain authoritative systems of work with corresponding corporate structures that have their roots in corporate architects and surveyors: senior managers. With this understanding, corporate manslaughter under the 2007 Act can operate as a conceptually coherent and practically functional basis of liability.

\section{Past Mistakes: the Identification Doctrine}

In the past, the law approached the transfer from individual to corporate liability through the use of the identification doctrine. The doctrine has its origins in the dependence of organisations on individual corporate members. Aside from being metaphysical fact, the reliance of organisations on individuals in order to act is legal doctrine: '[a] company is incapable of acting or speaking or even of thinking except in so far as its officers have acted, spoken, or thought'. ${ }^{8}$

\footnotetext{
${ }^{8}$ Director of Public Prosecutions v Kent \& Sussex Contractors Ltd [1944] KB 146, 155.
} 
On this approach, organisations were not simply incapable of independent action, but also independent thought. There could be no independent criminality by organisations. The result was that, for corporate liability to arise, there needed to be an individual who was the 'directing mind and will of the corporation, the very ego and centre of the personality of the corporation'. ${ }^{9}$

The central proposition of the identification doctrine is elicited from the case of Tesco Supermarkets $v$ Nattrass. ${ }^{10}$ At the core of the doctrine is the possibility for an individual within an organisation to become 'an embodiment of the company', such that 'his mind is the mind of the company. If it is a guilty mind then that guilt is the guilt of the company.' 11

Corporate liability was dependent upon the presence, or more often absence, of an individual who was the 'directing mind and will' of the organisation. ${ }^{12}$ The kernel of corporate liability was that one individual represented the organisation. When empowered with a sufficient amount of control over the operations of an organisation, such an individual was taken to act not just for, but also as that organisation. His mind, in directing those acts, was equated with the mind of the company, with the result that his acts and states of mind could be treated as corporate acts and states of mind. ${ }^{13}$

The liability of the organisation, on this model, derived from the participation of that individual in corporate criminality. The person in question stood for the organisation, equated with the organisation, such that his or her misdeeds were attributable to the

\footnotetext{
${ }^{9}$ Lennard's Carrying Co Ltd v Asiatic Petroleum Co Ltd [1915] AC 705 HL, 713.

${ }^{10}$ [1972] AC $153 \mathrm{HL}$.

${ }^{11}$ Tesco Supermarkets Ltd v Nattrass [1972] AC 153 HL, 170.

12 Jonathan Clough, 'Bridging the theoretical gap: the search for a realist model of corporate criminal liability' (2007) 18 Criminal Law Forum 267, 271.

${ }^{13}$ HL Bolton (Engineering) Co Ltd v TJ Graham \& Sons Ltd [1957] 1 QB 159 CA, 172.
} 
organisation just as much as they were to the individual. ${ }^{14}$ Aggregation of fault was not permitted: in order for liability to arise under this doctrine, there needed to be one identifiable individual who could be equated with the organisation. ${ }^{15}$ Neither acts nor intention could be drawn from a group working together; the identification doctrine was concerned with only an individual, not individuals, who stood for the company.

Organisations could not be liable without criminally liable acts by individuals. If individuals were not at fault, nor was the organisation. ${ }^{16}$ Corporate criminal liability extended only so far as the acts of "the board of directors, the managing director and perhaps other superior officers of a company who carry out functions of management and speak and act as the company'. ${ }^{17}$ Individuals who constituted the directing mind and will of the organisation did not have to be formally defined as company directors, but nevertheless it remained necessary to identify individuals who had 'management and control in relation to the act or omission' that was the basis of liability. ${ }^{18}$

The identification doctrine was a model of liability by proxy. The culpable acts at the heart of liability were always committed by an individual; they simply became corporate because of the importance of that individual within the organisation. ${ }^{19}$ Liability under the identification doctrine was a product of the power an individual had over an organisation. Individual behaviour was at the core of the doctrine; liability was individualist.

\footnotetext{
${ }^{14}$ Tesco Supermarkets Ltd v Nattrass (n 11), 170.

15 Attorney General's Reference (No 2 of 1999) [2000] QB 796 CA), 813.

${ }^{16}$ Manuel Velasquez, 'Debunking Corporate Moral Responsibility' (2003) 13 Business Ethics Quarterly $531,543$.

${ }^{17}$ Tesco Supermarkets Ltd v Nattrass (n 11), 171.

${ }^{18}$ El Ajou v Dollar Land Holdings Ltd [1993] EWCA Civ 4, [1994] BCC 143, 151, 154.

${ }^{19}$ James Gobert, 'Corporate killing at home and abroad - reflections on the Government's proposals' (2002) 118 Law Quarterly Review 72, 75.
} 
The insistence upon one directing individual, and the denial of aggregation, placed a significant practical limitation on corporate liability, for such an individual could only realistically be found in a small company. ${ }^{20}$ In order to attribute liability to an organisation for an act or omission, it was first "necessary to identify the natural person or person having management and control in relation to the act or omission in point' ${ }^{21}$ Both the actus reus and the mens rea of manslaughter had to be established against that individual before the organisation could be deemed liable for manslaughter. ${ }^{22}$

As a result, the identification doctrine was of little use as a means of holding organisations to account. It effectively precluded the prosecution of large organisations for corporate offences, which by their very size either prevented individuals from engaging in the thoughts or acts that the doctrine required, forcing the sharing of tasks between numerous individuals, or instead obscured individual action from view such that prosecution was impossible. ${ }^{23}$ It was simply unable to keep up with the reality of large organisations producing consequences that were far more than the product of one individual's direction.

This inability to respond to the reality of corporate misconduct had significant practical implications. In 1997 a Great Western Trains High Speed Train collided with a freight train in Southall, resulting in the deaths of seven passengers. ${ }^{24}$ The collision was a

\footnotetext{
${ }^{20}$ David Ormerod and Richard Taylor, 'The Corporate Manslaughter and Corporate Homicide Act 2007' (2008) 8 Criminal Law Review 589, 592.

${ }^{21}$ El Ajou v Dollar Land Holdings Ltd (n 18), 151.

${ }^{22} R v$ Coroner for East Kent, ex parte Spooner (1989) 88 Cr App R 10 DC, 16.

${ }^{23}$ Alexandra Dobson, 'The Corporate Manslaughter and Corporate Homicide Act 2007: A Symbolic Response' (2009) 17 Asia Pacific Law Review 185, 187.

${ }^{24}$ Attorney-General's Reference (No 2 of 1999) [2000] QB 796 CA, 802.
} 
consequence of the lone driver of the train packing his bag rather than looking for signals, and as a consequence missing two signals warning him of the train ahead. ${ }^{25}$

The accident was caused by a driver not looking where he was going. Equally, however, such negligence was only able to have such catastrophic effects due to corporate negligence in the way the train was operated. The rules of Great Western Trains allowed for two independent safeguarding systems, either of which on their own could have prevented the accident, to be deactivated. ${ }^{26}$ At the time of the accident, one system was broken and the other inactive, consistent with the dominant practice within the company. ${ }^{27}$ Nevertheless, the train ran without restriction at speeds exceeding 100 miles per hour.

Great Western Trains imposed no requirement to operate the train with safety measures in place, or with another driver present. ${ }^{28}$ The company's rules for running the train rendered passenger safety dependent upon the concentration of one driver, without regard to the need to operate the train safely when travelling at such high speeds. ${ }^{29}$ Without this corporate negligence, the negligence of the individual driver would not have caused the accident.

However, within Great Western Trains there was no individual who both embodied the company and committed gross criminal negligence. ${ }^{30}$ As a result, despite failings across the company, without which the disaster and the deaths would not have occurred, Great Western Trains was not liable for manslaughter. The only available option was recourse to

25 ibid.

26 ibid.

27 ibid.

28 ibid.

${ }^{29}$ ibid, 803.

30 ibid, 815. 
the Health and Safety at Work Act 1974: an approach with limited expressive force and practical effect that failed to respond to the seriousness of corporate killing. ${ }^{31}$

Larger organisations such as Great Western Trains engage in misconduct that is truly corporate. Corporate manslaughter in such cases is a consequence of companywide failings. However, the size and internal practices of such organisations mask the individual contributions that were necessary for liability under the identification doctrine. Consequently, no large companies were convicted of corporate manslaughter prior to the introduction of the 2007 Act. $^{32}$

In small organisations, the distinction between the person running it and the organisation itself is often minimal, so prosecution was considerably easier. However, as prosecution becomes easier under an individualist model of liability, it also becomes increasingly pointless. ${ }^{33}$ If there is little difference between the individual and the organisation, then there is little difference between individual and corporate liability. It became the case that corporate liability for manslaughter was only available when it was not needed.

\footnotetext{
${ }^{31}$ Home Office, Reforming the Law on Involuntary Manslaughter: the Government's Proposals (2000), 3.

${ }^{32}$ C. M. V. Clarkson, 'Corporate manslaughter: yet more Government proposals' [2005] Criminal Law Review 677.

${ }^{33}$ Wells (n 2), 100-101.
} 


\section{Current Problems: Senior Management Failure, or Just the Failure of Senior Managers?}

The new law of corporate manslaughter arrived in 2007, in the form of the Corporate Manslaughter and Corporate Homicide Act, coming into force the following year. ${ }^{34}$ It was preceded by more than a decade of widespread dissatisfaction over the law of corporate manslaughter, highlighted by high-profile tragedies that emphasised the disutility of the identification doctrine. One such event was the capsizing of the ferry Herald of Free Enterprise. Having travelled less than a mile from the entrance of Zeebrugge harbour, the Herald capsized, leading to the deaths of nearly 200 passengers and crew. ${ }^{35}$ The ship capsized because its bow doors were left open, the assistant bosun responsible for closing the doors asleep in his cabin. ${ }^{36}$

Had the assistant bosun not slept through the call to 'Harbour Stations' and instead fulfilled his duties, the Herald would not have capsized when it did. There is no doubting his personal, very immediate, responsibility. ${ }^{37}$ However, as was discovered in a subsequent investigation by the Department of Transport, responsibility for the disaster spread far beyond one crew member, or even the crew as a whole. Mistakes and failures persisted not just across the crew of the Herald but throughout the operator of the ship, Townsend Thoresen. Sheen J, leading the Department of Transport investigation, stated that 'from top to bottom the body corporate was infected with the disease of sloppiness'. ${ }^{38}$

\footnotetext{
${ }^{34}$ Corporate Manslaughter and Corporate Homicide Act 2007 (Commencement no 1) Order, SI 2008/40, art 2.

${ }^{35}$ Department of Transport, MV Herald of Free Enterprise: Report No. 8074 (HMSO, 1987), 1.

${ }^{36}$ ibid, 8 .

${ }^{37}$ ibid, 10.

38 ibid, 14.
} 
Culpability for the disaster at Zeebrugge was shared across the entirety of Townsend Thoresen, but no one individual was entirely to blame, such was the diffusion of fault. The result was that, despite the clear presence of a corporate fault, there could be no corporate liability, for there was no individual fault sufficient to satisfy the requirements of the identification doctrine. Without liable individuals, there could be no liable organisation. ${ }^{39}$

The 2007 Act was conceived and developed in the shadow of the inefficacy of the old law, as an attempt to establish a meaningful and useful corporate manslaughter liability. Under the new law, liability arises when the way in which the organisation's activities are managed or organised causes a death. ${ }^{40}$ It represents at the very least a shift away from the individualist model that was represented by the identification doctrine. ${ }^{41}$ The test at the core of the new Act is one of 'management failure' ${ }^{42}$ Liability derives from the way in which activities are managed or organised - not from the activities of any one senior individual. Management, rather than any individual, must be at fault for liability to arise. The question then is whether management failure is treated as a species of organisational failure, or a failure by managers.

\section{A. Aggregating Individual Action into Management Failure}

If the 2007 Act was simply a test of management failure, then the question of whether liability arose from the organisation itself or from a group of individuals would be

\footnotetext{
${ }^{39}$ Edwin Mujih, 'Reform of the law on corporate killing: a toughening or softening of the law?' (2008) 29 Company Lawyer 76, 78.

${ }^{40}$ Corporate Manslaughter and Corporate Homicide Act 2007, s 1(1).

${ }^{41}$ Ormerod and Taylor (n 20), 590.

42 ibid, 602.
} 
considerably more straightforward. However, while earlier incarnations of the new approach to corporate manslaughter were models of management failure, the final form of the Act adds an additional layer of complexity.

The history of the Act has been of a focus on organisational failure. Previous proposals for reform of the corporate manslaughter offence focused on the failure of the organisation as a system, rather than failures by individuals within that system. ${ }^{43}$ Management failure was explicitly a failing of the organisation, with corporate manslaughter committed by the organisation itself rather than any individual within it. ${ }^{44}$ The notion of requiring an individual to stand as a proxy for the organisation was removed from consideration, with attention firmly focused upon the organisation as a free-standing entity.

As enacted, the 2007 law seems to potentially change the focus of corporate manslaughter by requiring that the way in which the organisation's 'activities are managed or organised by its senior management is a substantial element' of the management failure. ${ }^{45}$ It looks to retain a significant focus on people by allowing the aggregation of individual failures by senior managers. ${ }^{46}$ There is no search for one blameworthy individual, but individual behaviour still looks to be at the core of liability. The shift from management failure to senior management failure marks a potential break with the prelegislative history of the Act.

\footnotetext{
${ }^{43}$ James Gobert, 'The Corporate Manslaughter and Corporate Homicide Act 2007 - Thirteen years in the making but was it worth the wait?' (2008) 71 The Modern Law Review 413, 417-418.

${ }^{44}$ Law Commission, Legislating the Criminal Code - Involuntary Manslaughter (Law Com No 237, 1996), para 8.20.

${ }^{45}$ Corporate Manslaughter and Corporate Homicide Act 2007, s 1(3).

${ }^{46}$ Ormerod and Taylor (n 20), 591-592.
} 
The significant changes introduced between the inception of the idea of reforming corporate manslaughter and the introduction of the law in its final form may be seen to mark a shift away from the organisational and a return to liability that is individualist, albeit not focused on any one individual. Individual behaviour is instead aggregated together, and this aggregate operates as a stand-in for the organisation in much the same way an individual would do under the identification doctrine. Such an approach assumes that senior managers, as those with the most power and control within the organisation, best represent the overall direction of that organisation. ${ }^{47}$ They are therefore the individuals who may be most appropriately taken to stand for the organisation. The proxy relationship has survived, on this interpretation of the 2007 Act.

The aggregative interpretation of liability in light of the senior management requirement creates two distinct categories of corporate fault: that originating from senior managers, and from maverick workers. ${ }^{48}$ The personal failures of those deemed sufficiently senior within the organisation take priority, with those operating at a lower level only able to contribute to such failings. An implicit assumption of those who may stand for the organisation has been created, creating a category of those with whom the organisation may be identified.

This interpretation of the senior management requirement represents a continuation, albeit in a slightly expanded form, of the identification doctrine. The change is only in how specific the identification taking place need be: more than one senior manager can be considered to stand for the organisation, and their independent actions need

\footnotetext{
${ }^{47}$ George R Skupski, 'The Senior Management Mens Rea: Another Stab at a Workable Integration of Organizational Culpability into Corporate Criminal Liability’ (2011) 62 Case Western Law Review 263, 270.

${ }^{48}$ Gary Slapper, 'Corporate Punishment' (2010) 74 The Journal of Criminal Law 181, 182.
} 
not reach the standard of criminal negligence. ${ }^{49}$ Only the sum total of behaviour need amount to a gross breach, and in this sense the Act is a move forward from the identification doctrine. It is an acknowledgement of the roles multiple individuals can have in corporate misconduct, and of the frequent importance of far more than just one individual within any large organisation.

Viewed as an aggregative approach to corporate liability, liability under the 2007 Act would, like the identification doctrine that preceded it, be a model of liability by proxy. The 2007 Act allows for aggregation of fault of individuals across the organisation. ${ }^{50}$ Nevertheless, senior managers must play a substantial role in this fault. Organisations are liable on this approach only because of individuals committing misconduct who are sufficiently important to the organisation for their fault to be equated with corporate fault. This interpretation of the Act is only a limited move to simply allow the consideration of more than one individual.

With only a limited move to aggregating individual fault, when treated in this way the senior management requirement imposes problematic constraints on liability. The senior management test can accommodate consideration of several senior corporate members, but it cannot accommodate either the reality of organisational fault, or the practical consequences of relying on individuals to stand for organisations. The 2007 Act is an ugly hybrid of individualist corporate liability and acceptance of organisational culpability. ${ }^{51}$

\footnotetext{
${ }^{49}$ Julian Harris, 'The Corporate Manslaughter and Corporate Homicide Act 2007: unfinished business?' (2007) 28 Company Lawyer 321.

${ }^{50}$ Law Commission, Criminal Liability in Regulatory Contexts (Consultation Paper No 195, 2010), para 5.93.

51 'The Corporate Manslaughter and Corporate Homicide Act 2007' [2007] Criminal Law Review 749, 750.
} 


\section{B. The Challenges of Categorising Senior Managers as Corporate Proxies}

The potential focus on aggregated individual fault has not yet arisen as an obstacle to conviction in court, as the Act has been used only to prosecute small companies. ${ }^{52}$ The organisations prosecuted so far consist of no more than a grouping of close-knit individuals, or even one individual. Such cases present no problem of identifying individuals, and no additional element added by any overarching organisation. Prominent individuals take the lead and liability rooted in their acts is unrestrictive.

The straightforwardness of convictions obtained under the new law belies the practical problems created by the senior management requirement. The impact of the 2007 Act has been severely diminished as a result of police reluctance to charge organisations with manslaughter, largely due to uncertainty over what needs to be proved, and against who. ${ }^{53}$ The prevalent understanding of the senior management requirement has discouraged prosecution, and undermined the efficacy of the new law. ${ }^{54}$

The sentencing guidelines accompanying the Act demonstrate a focus on large organisations, suggesting that fines 'will seldom be less than $£ 500,000$ and may be measured in millions of pounds', but this initial intent has not been reflected in cases prosecuted to date. ${ }^{55}$ The six sentences handed down so far have all fallen considerably below the guideline minimum fine of $£ 500,000$, in large part because they have been

\footnotetext{
${ }^{52}$ Michael Appleby, 'More questions than answers' (2012) 30 The Safety \& Health Practitioner 19.

53 'Police toiling with corporate manslaughter, say lawyers' (2009) [27] 4 The Safety \& Health Practitioner.

54 ibid.

${ }^{55}$ Sentencing Guidelines Council, Corporate Manslaughter \& Health and Safety Offences Causing Death Definitive Guideline (2010), 7.
} 
limited by the assets of the small companies convicted. ${ }^{56}$ The new law of corporate manslaughter has been restrictively applied to prosecute 'small limited companies with a hands-on senior management structure', preventing the Act from achieving its goal of prosecuting large organisations for corporate killings. ${ }^{57}$

If prosecutors turn to larger corporations, as they must surely do if the aims of the Act are to be attained, the conceptual issues underlying the new law will take on new importance. The 2007 Act was conceived as a means of resolving the serious difficulties inherent in prosecuting large organisations for manslaughter; however, the new law is itself potentially undermined by an aggregative interpretation of fault in the senior management requirement. These difficulties are reflective of the problematic framing of the senior management test, but also indicate broader problems with the reliance upon individuals as proxies for organisations, and individual fault as a proxy for organisational culpability.

The creation of a category of individuals assumed to be identifiable as the organisation is problematic. While at first glance it appears straightforward to create such a category, in practice the boundaries of senior management are unclear, and will always be open to abuse and evasion. With the possibility of different organisations implementing their own formal chains of command, there ceases to be any reliable means of identifying who can stand for the organisation. ${ }^{58}$ The senior management requirement may produce a

\footnotetext{
${ }^{56}$ Rebecca Connell, 'Seventh corporate manslaughter conviction: Cavendish Masonry' Lexology (12 June 2014) <http://www.lexology.com/library/detail.aspx?g=dec55208-9a3d-43c7-82e9-56cb4d3a29ea> accessed 12 July 2014.

57 'Boss fined after corporate manslaughter conviction' FleetNews (4 March 2014) $<$ http://www.fleetnews.co.uk/news/2014/3/4/boss-fined-after-corporate-manslaughter-conviction/49774/> accessed 12 July 2014.

${ }^{58}$ Mujih (n 39), 79.
} 
category of individuals to stand for the organisation, but it is not a fixed category, dependent instead upon job descriptions and complex questions of employment law. ${ }^{59}$

Moreover, senior rank itself does not necessarily imply that senior managers will play large roles in corporate manslaughter. This produces a universal escape-clause for corporate liability: place junior staff in charge of operations that present a legal risk, and avoid the possibility of senior management's substantial involvement. ${ }^{60}$ Fault by junior members cannot give rise to liability without the assistance of senior management fault. So long as senior management's hands remain clean, the organisation will not be liable.

The senior management requirement, in prescribing an unsettled and easily avoided category of individuals as the identifiers of corporate liability, risks undermining the 2007 Act's capacity for holding organisations to account for corporate manslaughter. Its complexity makes prosecution difficult and avoidance easy.

\section{The Problems of Aggregative Corporate Liability}

Beyond the problems of the senior management requirement lie even more fundamental difficulties arising from the use of individuals as proxies for corporate fault. This is for two related reasons. First, individual wrongdoing is sometimes hard to find, even when a large number of individuals are taken into consideration, and second, corporate wrongdoing will often be more than the sum of individual wrongdoing.

Individually culpable actors are difficult to find within organisations, and in some cases may not exist at all. ${ }^{61}$ Identifying responsible individuals becomes increasingly

\footnotetext{
${ }^{59}$ Ormerod and Taylor (n 20), 604.

${ }^{60}$ Gobert, 'The Corporate Manslaughter and Corporate Homicide Act 2007 - Thirteen years in the making but was it worth the wait?' (n 43), 429.

${ }^{61}$ Skupski (n 47), 284.
} 
difficult as organisations grow. It is often impossible to precisely define individual contributions to corporate outcomes. Even in the realm of senior management, individual contributions to the wrongful outcome in question may be difficult to identify. An individualist, even when aggregative, model of liability will always be undermined because of this. The nature of the organisation is that it produces corporate, not individual, outcomes. This hides individuals behind the organisation. We cannot always tell what exactly happened, or who did what, while individual actors are hidden under corporate shrouds. ${ }^{62}$ As such, we are unable to identify the faulty actor, or even actors, whose failings may stand as those of the organisation.

Individual action is extremely difficult to pinpoint in corporate settings. Moreover, even when individuals can be identified as having made some contribution to the faulty outcome, there may be no individual fault to be found. Multiple innocent actions, when combined within a corporate context, can produce consequences for which we wish to assign fault, to blame and punish, but for which no individual is in any way culpable. Corporate misconduct may arise from the interaction of blameless individuals that takes place within an organisation, and nothing more. It can be a product not of action, but of the effect organisations have in bringing those actions together. Even with individual actors in plain view, there may be no fault to identify or aggregate as corporate.

If the capsize of the Herald is considered within the framework of the 2007 act, then the limitations of aggregative corporate liability come to the fore. If aggregated senior management fault is deemed necessary as a substantial element of the wrongful conduct of the organisation, then it is difficult to identify what those failings would be. This is not due

\footnotetext{
${ }^{62}$ James W Harlow, 'Corporate Criminal Liability for Homicide: A Statutory Framework' (2011-2012) 61

Duke Law Journal 123, 149.
} 
to any obliqueness of managerial roles or contributions within Townsend Thoresen, but instead due to the fundamental problem with aggregative liability: the inability of individual conduct to account for the full extent of corporate criminality.

The Herald capsized in part because of fault by individuals. The crew made mistakes in performing their roles, and in developing the guidelines that defined those roles so too did senior managers. ${ }^{63}$ However, the contribution of individual failings to the disaster borders on insignificance when compared to the magnitude of systemic failures within Townsend Thoresen. Crew operated within routines that were both narrow and uncertain in scope and execution. ${ }^{64}$ At management level, the structure of corporate roles reduced awareness of problems and diminished the perceived need to resolve them. ${ }^{65}$ Between management and crew there existed critical failures of communication, with the ensuing differing expectations and standards leading to apathy at all levels. ${ }^{66}$ It was these systemic failures that were the substantial cause of the Herald's capsize - not fault by individuals.

The insufficiency or absence of fault by individuals in some cases of corporate misconduct points to the shortfall between the acts of individuals and corporate outcomes. Some events are not attributable simply to individuals or groups. Some actions, for example major disasters, are not achievable by individuals acting alone. They are the product of the interaction of contributions by many different actors, who each bear little, or even none, of the blame themselves. It is crucial to realise that this interaction would be impossible without the organisation facilitating and creating these interactions. Tragedies such as the

\footnotetext{
${ }^{63}$ Department of Transport (n 35), 8, 11.

${ }^{64}$ ibid, 8.

${ }^{65}$ ibid, 15.

66 ibid.
} 
capsizing of the Herald may be the product not of any failures by individuals, but of a fault at the organisational level. The effect of the organisation in bringing together action may result in blameworthy outcomes for which no individual has any personal responsibility ${ }^{67}$

Corporate crime can never fully be captured by the acts of individuals, even aggregated together. Organisations have a greater effect upon the world than the sum total of their individual members' actions. Corporate fault is not fault by one individual; nor is it fault by a collection of individuals. Individuals are part of corporate culpability, but their fault is never equal to that of the organisation. ${ }^{68}$ Corporate crimes are the product of more than just actions by individuals: they result from the way the organisation functions at an institutional level. ${ }^{69}$ Individuals within organisations may both act in ways that they would not otherwise have done if not pressed by corporate pressures, and their actions may have consequences that would not have arisen were it not for the corporate context.

People act differently when within organisations. The choices they make are a product both of their own determinations and the environment within which they are acting. Individuals engage in acts they would avoid in the absence of corporate pressure. ${ }^{70}$ They engage in thought and action in response to the stimuli they are faced with, while 'individual characteristics, cognition, affect, and behaviour are constrained by their context ${ }^{71}$ All individual behaviour takes place within a context, and both the intentions

\footnotetext{
${ }^{67}$ Kevin Gibson, 'Fictitious Persons and Real Responsibilities' (1995) 14 Journal of Business Ethics 761.

${ }^{68}$ Stephen Wilmot, 'Corporate Moral Responsibility: What Can We Infer from Our Understanding of Organisations?' (2001) 30 Journal of Business Ethics 161, 164.

${ }^{69}$ Charles R P Pouncy, 'Reevaluating Corporate Criminal Responsibility: It's all about Power' (2011) 41 Stetson Law Review 97, 110.

${ }^{70}$ Samuel W Buell, 'The Blaming Function of Entity Criminal Liability' (2006) 81 Indiana Law Journal 473, 492-493.

${ }^{71} \mathrm{~S}$ W J Kozlowski and K J Klein, 'A multilevel approach to theory and research in organizations: Contextual, temporal, and emergent processes' in K J Klein and S W J Kozlowski (eds), Multilevel theory, research and methods in organizations: Foundations, extensions, and new directions (Jossey-Bass 2000), 58.
} 
and actions of individuals are a product of this context as much as they are a product of the determinations made within it.

At the same time, the outcomes of these decisions are moulded by the corporate context. The same decision becomes very different within an institutional context, one which can either greatly enhance or diminish the impact and scope of individual acts. Falling asleep while assigned to safeguard a door is one thing, but to do so against the backdrop of organisational neglect can expand the consequences of one individual's acts far beyond their original scope. ${ }^{72}$

Organisations have the capacity to shape the course of individuals' acts, both at the point at which decisions are being taken, and when those decisions are having an effect upon the world. The overarching presence of an organisation hides individual fault, but it also adds an additional element to behaviour in the corporate context, with the effect that a model of corporate liability that focuses only on the people within the organisation will never capture the full extent of fault and blame arising in instances of corporate manslaughter. The senior management requirement, as it has been interpreted to this point, is not only practically flawed by its insistence upon a category of identifying individuals. It is also conceptually undermined by the insistence upon individuals being identified as the organisation in order to ground liability.

With the focus on individual fault comes an inability to capture the extent of corporate culpability in the kinds of events that the 2007 Act was conceived as a response to. Tragedies such as the sinking of the Herald were the result of corporate failure, not just individuals failing. Without acknowledgement of the independent importance of the

\footnotetext{
${ }^{72}$ R. B. Whittingham, The Blame Machine: Why Human Error Causes Accidents (Elsevier ButterworthHeinemann 2004), 120.
} 
organisation as more than just a collection of individuals, we cannot complete the picture of who - or rather what - is to blame. In situations where organisational failure makes up the whole picture - where systemic fault is such that no individual is in any meaningful sense to blame - we are left without any liability at all. ${ }^{73}$ There is a need to incorporate the organisation into the framework of corporate manslaughter liability, to achieve the original aims of the 2007 Act and capture precisely what is corporate about corporate culpability.

\section{Identifying the Additional Dimension of the Organisation}

The Herald capsized because the assistant bosun slept while he should have been attending to the bow doors. However, alongside individual failings, there was a faulty process on board the Herald. The standing orders issued to the Herald's crew enabled and encouraged mistakes. ${ }^{74}$ Other officers and crew came to view their roles narrowly. Another crewman working close to the bow doors, despite seeing that there was no one there to close the doors, stated 'It has never been part of my duties to close the doors or make sure anybody is there to close the doors. ${ }^{97} \mathrm{He}$ did neither, and while this may represent a mistake on his own part, it is also reflective of a faulty corporate process at work. Moreover, beyond narrow roles, there were uncertain routines for performing those roles together. ${ }^{76}$ Crew and officers did not know exactly what they needed to do, but thought that they did not have to do much. The organisation of the crew and officers created a situation that allowed for the

\footnotetext{
${ }^{73}$ Gibson (n 67), 761.

${ }^{74}$ Department of Transport (n 35), 5.

75 ibid, 8.

76 ibid, 9.
} 
doors to be left open and unsupervised. ${ }^{77}$ The established procedures in place created the context for the disaster.

Beyond the crew of the Herald, the managers of Townsend Thoresen themselves made mistakes that contributed to the disaster, but they, like the crew of the Herald, worked within an environment that contributed to, and enhanced the impact of, those mistakes. Members of the management team were detached from responsibility that they needed to take, over matters such as specifying the duties of the Herald's officers. ${ }^{78}$ Due to the way in which roles were structured at the level of management, there existed a responsibility 'vacuum' ${ }^{79}$ At the same time, the modes of communication within Townsend Thoresen prevented individuals from recognising the need for change. Despite officers frequently sending memos expressing concern over the way in which ships were operated, one member of management stated in evidence that if an officer had been genuinely concerned by a problem with the operation of the ships 'he would have come in and banged on my desk'. ${ }^{80}$ The expectations and standards of communication differed greatly between management and crew, leading to apathy at both levels. This apathy, in part, caused the disaster.

There is no doubting that the action, and inaction, of a number of employees of Townsend Thoresen contributed to the Herald's capsize and the subsequent loss of life. However, beyond any individual, Townsend Thoresen itself had a significant role in the tragedy. The corporation established a system within which its employees worked. As can

\footnotetext{
77 ibid, 8 .

78 ibid, 15 .

79 ibid.

${ }^{80}$ ibid, 26.
} 
be seen, that system had an internal structure of processes that determined the way in which things were done, and this created the context for the disaster.

\section{A. The Authority of Corporate Structures}

At the core of any corporate entity is the contract between the employing organisation and the employee, who agrees to follow direction in exchange for remuneration. ${ }^{81}$ The individuals who work for organisations enter into authority relationships, through which their acts are directed. Organisations can direct employees on when they work, what work they do and how they do it. ${ }^{82}$

The authority of organisations imposes a system of work: a context within which employees operate. Individuals do not just work for organisations: they work within them. The employer status of organisations is such that, alongside the relationship in law between organisation and individual, there is a relationship of authority in fact. Organisations are not simply legal constructs, but employers, establishing authoritative systems of work with control over the context in which their employees act.

As a part of this system, inherent in all large organisations, is a corporate structure. This includes the formal setting of the organisation: the rights and duties of different members to act independently, and how group members are organised, evaluated and awarded.$^{83}$ The pressure of the organisation is not necessarily expressed through coercion, or threats. The mob, a large corporation, or any other organisation may impose its authority

\footnotetext{
${ }^{81}$ Coase, (n 3), 391.

82 ibid, 404.

83 James A Brickley, Clifford W Smith Jr and Jerold L Zimmerman, 'Business ethics and organizational architecture' (2002) 26 Journal of Banking \& Finance 1821, 1822.
} 
through the offer of positive benefits for acting in a particular way. ${ }^{84}$ Money is not the only possible incentive; rewards may instead include 'corner offices, parking places, dining room privileges, and the like' ${ }^{85}$

Corporate structure can exist in codes, rules, or guidance; in remuneration, promotion or firing schemes; or in the way in which these processes are imposed and monitored. ${ }^{86}$ Alongside formalised corporate practices, procedures and policies, corporate structure may also be both informal and unwritten, yet remain embedded in the organisation. Structure extends far beyond what is written down. ${ }^{87}$ There may be particular language used to frame issues, or informal implicit requirements or goals. ${ }^{88}$ Corporate structure can include the means, or lack thereof in organisations like Townsend Thoresen, of communication between corporate members. ${ }^{89}$ Organisations may not explicitly tell individuals what to do, but informal structures can still cause individual perceptions and decisions to fall in line with organisational standards. ${ }^{90}$ Informal structural constraints can determine the importance and meaning of rules or codes, or of job descriptions, and may even contradict those put forward officially as corporate practice. ${ }^{91}$

Whether formally expressed or not, corporate structure can be observed as part of the corporate system of work. Its effects may be seen in 'technology, office layout, manner

\footnotetext{
${ }^{84}$ Shachar Eldar, 'Punishing Organized Crime Leaders for the Crimes of their Subordinates' (2010) 4 Criminal Law and Philosophy 183, 185.

85 James A Brickley, Clifford W Smith Jr and Jerold L Zimmerman, 'Corporate Governance, Ethics, and Organizational Architecture' (2003) 15 Journal of Applied Corporate Finance 34, 42.

${ }^{86}$ Milton C Regan Jr, 'Moral Intuitions and Organizational Culture' (2007) 51 Saint Louis University Law Journal 941, 942.

${ }^{87}$ Brickley, Smith Jr and Zimmerman (n 83), 1828.

${ }^{88}$ Linda K Treviño, Gary R Weaver and Scott J Reynolds, 'Behavioral Ethics in Organizations: A Review' (2006) 32 Journal of Management 951, 962.

${ }^{89}$ Harlow (n 62), 124.

${ }^{90}$ Pamela D Schultz, 'The Morally Accountable Corporation: A Postmodern Approach to Organizational Responsibility' (1996) 33 Journal of Business Communication 165, 174.

${ }^{91}$ Nico Jorg and Stewart Field, 'Corporate liability and manslaughter: should we be going Dutch?' [1991]

Criminal Law Review 156, 169.
} 
of dress, visible or audible behaviour patterns, and public documents such as charters, employee orientation materials, stories'. ${ }^{92}$ The origins of such policies, practices and procedures may be traced back to the organisation, a system of work that implements a corporate structure into the context of employee action.

The pressures imposed by corporate structure are not always formal or explicit, and they may at first glance seem trivial, but even implied insistence on a dress code can change the way people think and behave. Enforcing the adoption of a single corporate uniform can have significant effects upon the choices of those wearing corporate attire. ${ }^{93}$ Whether formally expressed or not, corporate structure establishes an environment that can change the behaviour of employees. The structure of an organisation can both encourage and impede the actions of corporate members.

Corporate structure determines the context in which individual employee action takes place. Through this context, the organisation expresses its values, norms, basic ideas and mode of operations. ${ }^{94}$ By controlling the context of employee action, the organisation coerces compliance with corporate goals and aims. It imposes pressure upon employees, implicitly or explicitly, changing actors' perceptions or understanding of what they should or should not do. Corporate structure is capable of constructing a 'psychic prison', an environment in which the organisational standards imposed overbear individual autonomy. ${ }^{95}$ Individual autonomy is in this way bounded by organisational structure. ${ }^{96}$

\footnotetext{
${ }^{92}$ Edgar H Schein, 'Coming to a New Awareness of Organizational Culture' (1984) 25 Sloan Management Review 3.

${ }^{93}$ Schultz (n 90), 172-173.

${ }^{94}$ Mats Alvesson and Per-Olof Berg, Corporate Culture and Organizational Symbolism (Walter de Gruyter 1992), 77.

${ }^{95}$ Gareth Morgan, Images of Organization (Sage Publications 2006), 211.

${ }^{96}$ Schultz (n 90), 169.
} 
The corporate system of work imposes a system of behaviour upon employees within organisations. ${ }^{97}$ Acts furthering corporate goals are required as a condition of employment. ${ }^{98}$ The choices available to an actor diminish, and he is pushed down paths as he is constrained by the authoritative environment of the organisation. ${ }^{99}$ Corporate structure can define both the boundaries, and the direction, of the actions to be taken within the organisation. ${ }^{100}$ Individuals are pressured to act in accordance with 'organizational goals and interests', as determined from an organisational perspective. ${ }^{101}$ Decisions become the product not of individual perceptions, but of the organisation's implicit or explicit priorities.

Corporate structure alters the perceptions of individuals working within its bounds. It controls the boundaries of interpretation and understanding within the organisation, changing the reasons individuals have to act and thereby changing their actions. ${ }^{102}$ Individual perceptions are altered, such that corporate goals become personal aspirations, to be attained in accordance with the organisation's practices. Within the psychic prison of the organisation a 'moral microcosm' forms. ${ }^{103}$ In this way, corporate structure determines individual behaviour. ${ }^{104}$

\footnotetext{
${ }^{97}$ Edwin H Sutherland, 'White-Collar Criminality' (1940) 5 American Sociological Review 1, 11.

${ }^{98}$ James William Coleman, 'Toward and Integrated Theory of White-Collar Crime' (1987) 93 American Journal of Sociology 406, 423.

${ }^{99}$ Pursey Heugens, 'A Neo-Weberian Theory of the Firm' (2005) 26 Organization Studies 547, 560.

${ }^{100}$ Anderson (n 5), 228.

${ }^{101}$ Yoash Wiener, 'Commitment in Organizations: A Normative View' (1982) 7 THe academy of Management Review 418, 421.

${ }_{102}$ Morgan, (n 95), 211.

${ }^{103}$ Arthur P. Brief, Robert T. Buttram and Janet M. Dukerich, 'Collective Corruption in the Corporate World: Toward a Process Model' in M. E. Turner (ed), Groups at Work: Theory and Research (Lawrence Erlbaum Associates 2001), 484.

${ }^{104}$ Stewart Clegg, Martin Kornberger and Carl Rhodes, 'Organizational ethics, decision making, undecidability’ (2007) 55 The Sociological Review 393, 406.
} 
Corporate structure is not a collection of individual contributions, or 'built' by individuals. It builds itself, adapting to pressures imposed both by individuals and social context. ${ }^{105}$ It responds to pressures from outside as well as within the organisation, by directing the behaviour of individuals through the creation of a context for action. ${ }^{106}$ When actors are operating in such a context then their acts are not only the product of their own decisions. They are also a product of the system of work in which those decisions were taken. ${ }^{107}$ Structure drives and determines individual behaviour, establishing the explicit involvement of the organisation in corporate crime.

Corporate structure changes the relationship between the organisation and its members. Individuals operating within the organisation act not only for the organisation: they also act because of it. The behaviour of corporate members is directed and controlled by formal guidance, informal procedures and the composition of authority within the organisation. ${ }^{108}$ Organisations are potentially culpable directors of acts by individuals.

Criminal liability arises from a criminal act, but its reach is not limited solely to the actor himself. One can be criminally responsible for an action on the basis that one directed, rather than performed, the act in question. Criminal liability for a death is not always a product of pulling the trigger. Aiding, abetting, counselling or procuring an offence is just as indictable as actually committing that offence. ${ }^{109}$ Individuals become liable in this way, and so may organisations. Liability as a counsellor is a product of one's authority over the

\footnotetext{
${ }^{105}$ Michael Lounsbury and Marc Ventresca, '1. Social structure and organizations revisited' in Michael Lounsbury and Marc Ventresca (eds), Social Structure and Organizations Revisited (Research in the Sociology of Organizations, Volume 19) (Emerald Group 2002), 26.

${ }^{106}$ Lounsbury and Ventresca (n 4), 459.

${ }^{107}$ Susanna K Ripken, 'Corporations are people too: a multi-dimensional approach to the corporate personhood puzzle' (2009-2010) 15 Fordham Journal of Corporate \& Financial Law 97, 136-137.

${ }^{108}$ Jorg and Field (n 91), 165.

${ }^{109}$ Accessories and Abettors Act 1861, s 8.
} 
triggerman, making it possible to be guilty of homicide without directly killing, solely on the basis that one counselled the commission of the offence. ${ }^{110}$

Corporate structure need not insist upon death, for whenever a killing is within the scope of one's instruction or authorisation, counselling an offence renders one a principal party in that crime. ${ }^{111}$ Organisations, through their corporate structures, direct individuals to engage in acts with the potential to cause death. As directors, organisations commit manslaughter in their own right, without regard to any individual fault.

Organisations are independently culpable. Their liability would not arise without employees, but rather than acting as a proxy for organisations, individuals may be treated a conduit through which the directorial liability of the organisation is channelled. There is no need to identify those who stand for the organisation, or to search for aggregated individual fault. Organisations may be criminally liable for the effects their structures, which derive their power from the system or work that the organisation imposes as an employer, have in determining the direction and boundaries of individual action. The task now is to interpret the senior management requirement of the 2007 Act in this light, and to find a purpose for the test against the backdrop of the possibility of corporate culpability.

\section{B. Realigning the Senior Management Requirement}

The senior management requirement operates as a limit on corporate liability for manslaughter. Both where this boundary lies, and what considerations it has regard to, must be reassessed in light of the potential of organisations to commit manslaughter without the need for an identifying individual. Previously, the test has been seen as a means of defining

${ }^{110} R v$ Calhaem [1985] QB 808 CA, 813.
${ }^{111}$ ibid. 
those individuals who could be identified as standing for the organisation. With corporate structure brought to the fore, senior management may instead be recognised as a means of defining policies, practices and procedures that are corporate, rather than incidental to the organisation.

Not everything that dominates within an organisation is corporate, in the sense that it is part of the system of work within the organisation. Corporate culture is corporate in so far as it exists within the corporate entity, but it does not necessarily originate in the corporate system. ${ }^{112}$ Corporate culture is a product of what goes on between individuals, of the relationships and interactions between members. Some of these cultural traits will be bottom-up, emerging from the acts of individuals. ${ }^{113}$ They will have no structural origin, and as a result the culture of an organisation may not be attributable to the structures of that organisation. It may instead flow from the dominance of a particular individual. ${ }^{114}$ Alternatively, it may be a product of the interactions and relationships between group members. ${ }^{115}$

Corporate culture describes the pressures that originate, and are felt, as a consequence of group-level value emergence and identification. ${ }^{116}$ Their influence is a product of identification with the group, rather than direction by structure. ${ }^{117}$ While the pressures that corporate culture imposes may overlap with those imposed by corporate structure, corporate culture is incidental to the corporate context. Corporate culture is not

\footnotetext{
${ }^{112}$ Lynne L Dallas, 'A preliminary inquiry into the responsibility of corporations and their officers and directors for corporate climate: the psychology of Enron's demise' (2003-2004) 35 Rutgers Law Journal 1, 3.

${ }^{113}$ Kozlowski and Klein, (n 71), 9.

${ }^{114}$ Dallas (n 112), 21.

${ }^{115}$ S W J Kozlowski and B F Bell, 'Work Groups and Teams in Organizations' (2001)

DigitalCommons@ILR < http://digitalcommons.ilr.cornell.edu/articles/389/> accessed 12 July 2014, 6.

${ }_{116}$ Kozlowski and Klein (n 71), 10.

117 James March and Herbert Simon, Organizations (2nd edn, Blackwell 1993), 79.
} 
part of the corporate system of work. It is not a matter of corporate responsibility, but of group responsibility.

Corporate responsibility is concerned with the overarching structure, implemented from above, that governs those interactions. It exists outside, and above, groups. ${ }^{118}$ The importance of the organisation in relation to its responsibility is the context it, through the imposition of a system of work, creates. ${ }^{119}$ Group dynamics occur incidental to the corporate context, changing the way individuals interact. Groups modify our interactions with one another, but corporate structure sets the rules for and boundaries of these interactions. Corporate systems impose overarching structural pressures and constraints, whereas group dynamics are interpersonal. ${ }^{120}$ Only the former are truly corporate, rather than incidental to the corporate context. Corporate policies, practices and procedures are those that are embedded by a process of acceptance, whether active or passive, by senior corporate members.

When holding organisations responsible, there is a need to identify what is truly corporate. With this need in mind, the senior management requirement may be seen not as an awkward addition to the law, but as an essential requirement for preventing corporate responsibility from extending beyond the corporate and into the incidental. Senior managers, within the meaning of the act, are those who make decisions about, or participate in, managing or organising the organisation. ${ }^{121}$ Requiring their substantial involvement in the corporate offence need not imply that they be involved as faulty actors, but instead may be interpreted as an acceptance of their necessary involvement in corporate structure.

\footnotetext{
${ }^{118}$ Kozlowski and Bell (n 115), 6.

119 Dallas (n 112), 9.

${ }^{120}$ Kozlowski and Bell (n 115), 17.

${ }^{121}$ Corporate Manslaughter and Corporate Homicide Act 2007, s 1(4)(a).
} 
Corporate structure is not limited by its initial design. ${ }^{122}$ However, that which is corporate will always require a level of adoption or toleration that only senior members of an organisation are in a position to engage in. If practices are to become embedded at the corporate, rather than group, level, they must receive institutional acceptance. They must become embedded as corporate values, and in considering how this may occur the role of senior members of organisations comes to the foreground. Whether through explicit adoption or informal toleration, senior members of a corporation play a central role in the institutionalisation of the processes and constraints that go on to become part of the corporate system of work. The senior members of an organisation define rules and select members, establishing the basis for future structural evolution. ${ }^{123}$ They are central to the adoption of procedures, policies, and practices into the corporate structure. ${ }^{124}$

In building its own structures, the corporate system of work is an autonomous and independent entity. However, every building has architects and surveyors who direct and oversee structure. Such individuals play substantial contributory roles in the development of structures. Just as physical structures have architects and surveyors, so too do corporate structures. It is in occupying these roles that senior managers take on substantial roles in corporate systemic fault. Corporate structure implies architects and surveyors: members of senior management who play a significant role, whether active or passive, in the development and oversight of the corporate system of work. ${ }^{125}$

\footnotetext{
${ }^{122}$ Pratt, Gordon and Plamping, (n 6), 13.

${ }^{123}$ Dickson and others (n 7), 201.

124 ibid, 208.

${ }^{125}$ Kenneth E Goodpaster, 'The Concept of Corporate Responsibility' (1983) 2 Journal of Business Ethics 1,20 .
} 


\section{Testing for Corporate Structure with the Senior Management Requirement}

The argument has sometimes been made that corporate liability under the new Act derives from individual fault and culpability. ${ }^{126}$ In light of the capacity of organisations to be independently at fault and culpable, this need not be the case. Individual behaviour enables corporate culpability, but individual fault is no longer a prerequisite for a finding of corporate liability.

Senior managers, within the meaning of the act, are those who make decisions about, or participate in, managing or organising the organisation. ${ }^{127}$ Requiring their substantial involvement in the corporate offence does not imply that they be involved as faulty actors, and may instead be interpreted as an acceptance of their necessary involvement in corporate structure. The senior management test will necessarily always involve individuals, but need not be a test of individual fault.

Instead, the senior management test may be viewed in light of the need to distinguish between corporate structure and that which is incidental to the corporate context. It can be a means of removing group and individual factors from the picture, concentrating instead on the role of the organisation itself. Senior management failure is a form of management failure, and need not imply any move into individual liability as a condition of organisational liability. ${ }^{128}$ Senior management establish and oversee the blueprint of the corporate structure. Though this structure extends far beyond senior

\footnotetext{
${ }^{126}$ Neil Cavanagh, 'Corporate criminal liability: an assessment of the models of fault' (2011) 75 Journal of Criminal Law 414, 424.

${ }^{127}$ Corporate Manslaughter and Corporate Homicide Act 2007, s 1(4)(a).

${ }^{128}$ Rosemary Craig, 'Thou shall do no murder: a discussion paper on the Corporate Manslaughter and Corporate Homicide Act 2007’ (2009) 30 Company Lawyer 17, 19.
} 
managers' input, those managers will always have an architectural or oversight role in the creation or toleration of corporate structure. ${ }^{129}$

Central to the senior management requirement is not the managers themselves, but how they manage or organise the organisation, such that 'how the activities were managed or organised by senior management must be a substantial element of the gross breach' ${ }^{130}$ The importance of senior managers, in the context of the Act, is their role in 'conceiving, formulating, approving and implementing corporate policies' that form a substantial part of the offence. ${ }^{131}$ Senior management is defined by reference to the having of significant roles in determining the trajectory of the organisation: in making decisions about how it is managed or organised, and engaging in such management and organisation. ${ }^{132}$ Senior managers are not classified as such because of their particular designated title, but by reference to their role within the organisation, their capacity to oversee and change the course of its policies.

The powers and control that define senior management equate to the capacity to make architectural decisions and occupy surveyor's roles. Senior managers are able to determine not only their own goals or those of subordinates, but also organisational goals. They do so by institutionalising the processes, policies, and procedures that make up corporate structure. Senior managers of organisations are defined not by their formal position within the organisation, but by reference to their architectural and oversight roles. Senior managers are individuals empowered to make decisions about the organisation.

\footnotetext{
${ }^{129}$ Constantine Ntsanyu Nana, 'Corporate Criminal Liability in South Africa: The Need to Look Beyond Vicarious Liability’ (2011) 55 Journal of African Law 86, 103.

${ }^{130}$ Explanatory notes to the Corporate Manslaughter and Corporate Homicide Act 2007, para 14.

${ }^{131}$ Gobert, 'The Corporate Manslaughter and Corporate Homicide Act 2007 - Thirteen years in the making but was it worth the wait?' (n 43), 414.

132 Corporate Manslaughter and Corporate Homicide Act 2007, s 1(4)(c).
} 
Through their management oversight and control, senior managers are in a position to supervise and direct, with action or inaction, whether intentionally or through inattention, the trajectory of the organisation. They control the foundations of corporate structure, and in this way delineate the boundaries of corporate liability for manslaughter. Their contributions represent a substantial element of culpable corporate structure.

The senior management requirement functions without regard to the presence or absence of misconduct by senior managers themselves. The 2007 Act requires the management and organisation of corporate activities by senior management to be a substantial element of the offence, but does not specify the necessary manner of this involvement. ${ }^{133}$ There is no requirement within the act for the individuals who make up senior management to contribute to any criminal act, so long as senior management remains a substantial element of the corporate crime. There is no requirement that senior managers are at fault, or that corporate liability derives from the aggregated culpability of individuals.

Senior managers themselves need not be substantially involved in events giving rise to corporate manslaughter liability, which ceases to be matter of aggregating the misconduct of senior management members. It is not the members of senior management themselves that matter, nor any fault on their part, but rather their characteristic involvement as architects and surveyors that facilitate development of corporate structure. Through occupying these roles, members of senior management have a significant and substantial role in corporate crime. ${ }^{134}$

\footnotetext{
133 ibid, s 1(3).

${ }^{134}$ Skupski (n 47), 310.
} 
With this interpretation of the senior management requirement, the Corporate Manslaughter Act becomes a model of corporate culpability. The liability of an organisation is indicated by the involvement of individuals who play a particular role, and have particular significance, within that organisation. When corporate structure, marked by the involvement of senior management, causes death, the organisation is liable. When corporate structure alters the decisions of individual employees, it becomes capable of causing them to act in a way that causes death. Corporate manslaughter liability arises when the way in which the organisation is managed or organised causes death. ${ }^{135}$ Corporations are liable due to the effect of the system of work on individual action, with no further causal link required. There is no need to enquire into the fault of individuals, whether senior manager or otherwise. ${ }^{136}$

The resulting corporate liability is posited not on corporate culture or individuals fault incidental to the corporate context, but on the directorial role of organisations. Senior managers establish, direct and supervise the corporate structure that enables organisations to determine the action of others. Organisations are liable for the acts they facilitate, direct and induce. Senior management's statutory significance is that their architectural and supervisory involvement provides evidence of a culpable corporate structure.

Understood in this way, the senior management requirement restricts corporate responsibility, but does so in a way that emphasises the role of the corporate entity. What matters, under the new test, is how activities are 'managed or organised' by senior management - not the senior managers themselves. ${ }^{137}$ This strikes the contrast between the

\footnotetext{
${ }^{135}$ Corporate Manslaughter and Corporate Homicide Act 2007, s 1(1)(a).

136 cf Gobert, 'The Corporate Manslaughter and Corporate Homicide Act 2007 - Thirteen years in the making but was it worth the wait?'(n 43), 418.

${ }^{137}$ Corporate Manslaughter and Corporate Homicide Act 2007, s 1(4)(c).
} 
corporate and the group, not between high-up and low-down individuals, but between bottom-up and top-down pressures and constraints. The senior management requirement allows for the identification of what is truly corporate. It distinguishes the corrupt organisation from the 'organisation of corrupt individuals' ${ }^{138}$

This approach brings a far more flexible scheme of liability, immune to the complexities of employment law and the complications of role definition within organisations. With the focus on roles, rather than titles, job descriptions become irrelevant. Once the inherent involvement of senior management at the architectural and oversight level is recognised, then even a junior member's running of corporate activities can be traced back to the organisation, through the contributions of senior managers and into the faulty corporate environment in which that junior was operating.

The framework of corporate structure highlights the contributions of senior managers, corporate structures and acting employees to corporate misconduct. Both the origins and effects of culpable corporate structure are easily observed. At Enron, for example, rules concerning 'role modelling, allocation of rewards and criteria for selection and dismissal' emanated from senior management into Enron's corporate structure, enabling and encouraging 'lying, cheating and stealing' across the company. ${ }^{139}$ These significant effects offer a basis of culpability and liability, both for structural traits and architectural contributions.

\footnotetext{
138 Jonathan Pinto, Carrie R Leana and Frits K Pil, 'Corrupt Organizations or Organizations of Corrupt Individuals? Two Types of Organization-Level Corruption' (2008) 33 Academy of Management Review 685.

${ }^{139}$ Yadong Luo, 'An Organizational Perspective of Corruption' (2004) 1 Management and Organization Review 119, 126.
} 
Awareness of the culpability of corporate structure enhances the picture of the responsibility of and within organisations. Senior managers, as corporate architects and surveyors, take on newfound responsibility by virtue of their duties to regulate the corporate system of work. Senior members of an organisation are responsible for the development of organisational policies, practices and procedures that underlie corporate structure. ${ }^{140}$ Senior managers of organisations are placed in positions of responsibility. They govern a dangerous environment, and are responsible for fulfilling their architectural and oversight roles in doing so. The senior members of an organisation may be responsible both for developing, and failing to develop, corporate structure. The culpability of corporate structure implies culpable senior managers.

Treating senior management as evidence of corporate culpability is in line with the original intent of the Commission in developing a new law of corporate manslaughter. The intended question was to be of whether there was management failure as distinct from 'blameworthy conduct on the part of any individual or group of individuals which should be attributed to the company'. ${ }^{141}$ Support for this approach can be seen throughout the Act: the focus of the offence is the manner in which the organisation's activities are organised, with the jury able to consider the existence of 'attitudes, policies, systems or accepted practices' that could have encouraged or produced tolerance of management failure. ${ }^{142}$

A concept of corporate culpability is consistent with the judicial direction taken so far in the limited case-law concerning the 2007 Act. Judicial interpretation corresponds with the theoretical model proposed here, as in $R v$ Cotswold Geotechnical Holdings Ltd, ${ }^{143}$

\footnotetext{
${ }^{140}$ Dickson and others (n 7), 208.

${ }^{141}$ Law Commission, Legislating the Criminal Code - Involuntary Manslaughter (n 44), para 8.20.

142 Corporate Manslaughter and Corporate Homicide Act 2007, s 8(3)(a).

143 [2011] EWCA Crim 1337, [2012] 1 Cr App R (S) 26.
} 
in which the defendant corporation was convicted for 'manslaughter causing death as a result of a gross breach of duty following a system of work which was demonstrably, and for some time had been, unsafe, with the potential for causing death' ${ }^{144}$ Corporate liability has been treated as a product not of individual fault, but of a faulty system of work.

With this interpretation, cases exhibiting similar attributes to the capsize of the Herald may be regarded as clear instances of corporate criminal liability for manslaughter. The system of work at the centre of that disaster is brought to the fore, and its significant contributions to individual failings are recognised as the origins of corporate manslaughter.

Through acknowledgement of senior managers as architects and surveyors, senior management involvement may continue to be used as evidence of systemic failure. This is not a failure by an individual or group of individuals, but a systemic failing that has its scope circumscribed by the involvement of certain individuals, as architects and surveyors of a system of work. Only by recognising the senior management requirement as pointing to the structural constraints and pressures of organisations is it possible to succeed in capturing the responsibility of organisations. Only this approach will succeed in truly broadening the net of corporate liability. ${ }^{145}$

\section{Structural Failure, Corporate Culpability, and a New Role for Senior Management}

With the arrival of the Corporate Manslaughter and Corporate Homicide Act 2007 comes a new means of approaching the criminal liability of organisations. There is the potential

\footnotetext{
${ }^{144} R v$ Cotswold Geotechnical Holdings [2011] EWCA Crim 1337, [2012] 1 Cr App R (S) 26, 157.

$145 \mathrm{cf}$ Dobson (n 23), 198.
} 
for a significant shift away from the individualist history of corporate liability, towards a model that reflects the role and responsibility of organisations. It allows for the consideration of organisational liability as something held by the organisation: not just by its members. The risk, however, is that the new law is interpreted in an overly restrictive manner, and constrained to consideration of aggregated individual fault. Such an approach would undermine the aims of the Act, rendering the new law almost as unhelpful as its predecessor and fraught with complications.

There is space, however, for consideration of the 2007 Act as more than just a means of attributing individual conduct to organisations. It may be recognised as a move towards recognising the participation of senior managers as a marker for a distinctly corporate culpability. ${ }^{146}$ The role of the senior management requirement need not be used to identify individual failure, but to define the limits of organisational failure. Individuals remain important to corporate liability, but only in so far as they indicate the boundaries of corporate structure. Senior managers matter not because they represent the organisation, but because they are the architects and surveyors of its structure. Organisations are not liable because of individuals, but due to the directorial role of their authoritative structures. Certain individuals demarcate corporate structure, and the provisions of the new Act focus our attention on exactly those individuals: senior management.

The test of senior management points not to a conceptual confusion, but instead to a narrow focus on the corporate, rather than the individual or group, by emphasising the architectural and oversight role of senior managers. With this interpretation, the Act becomes a powerful tool for the prosecution of corporate manslaughter, able to

${ }^{146}$ Clough (n 12), 296. 
accommodate the diversity of large organisations. The 2007 Act can encompass the full extent of corporate culpability. 